\title{
Dermatological Signs and Symptoms of Measles: A Prospective Case Series and Comparison with the Literature
}

\author{
Raphael Battegay ${ }^{a}$ Christoph Itin ${ }^{b}$ Peter Itin ${ }^{a}$ \\ ${ }^{a}$ Department of Dermatology, University Hospital Basel, Basel, and ${ }^{b}$ Private practice, Liestal, Switzerland
}

\section{Key Words}

Measles $\cdot$ Natural course $\cdot$ Clinical signs and

symptoms $\cdot$ Description in textbooks

\begin{abstract}
Background/Aims: Because of high vaccination rates, population immunity against measles increased in the western world. Nevertheless, outbreaks are still observed. The aim of this article is to document and describe the natural course of dermatological manifestations and compare it with the literature. Methods: After detecting a measles index case, the dermatological onset of the disease in the non-vaccinated siblings was prospectively monitored and documented with a digital camera. Results: Our findings show that dermatological symptoms are only limited consistently from one case to another and described heterogeneously in the literature as well. Conclusion: Dermatological manifestations do not seem conclusive in our clinical data set as well as in the literature. Especially the exact onset of the Koplik spots should be further explored in detail. In future, a larger population should be observed and clinical diagnostics for measles defined.
\end{abstract}

Copyright $\odot 2012$ S. Karger AG, Basel

\section{Introduction}

Measles is a highly contagious infection by a paramyxovirus. Since there exists a vaccine against the disease, it is nowadays not as common as it used to be. However, vaccination compliance has decreased dramatically, and therefore measles still produces outbreaks and can become dangerous in various circumstances [1]. Not only for that reason is it important to recognize the clinical presentation in an early stage.

In this case series, we intend to describe the clinical onset of this infection and compare the outcome to findings in the literature.

\section{Epidemiology}

Recent surveys show that measles are still present in Europe, especially in Romania, Germany, the UK, Switzerland and Italy, despite efforts to eradicate the disease [2]. Also adults aged 20 years or older are more and more affected.

Since 1999 the notification of measles has been mandatory in Switzerland. From November 2006 to February 2008, 1,405 measles cases were reported by physicians or laboratories [3]. This gives an incidence for all ages of 19 cases/100,000 inhabitants in this period of time. Two peaks were observed during this outbreak. One occurred in August 2007, followed by a second peak in January 2008. The numbers of the Swiss health department show a third peak in March 2009 and January 2011. The incidence rates in different areas correlated with their vaccination coverage.

\section{Signs and Symptoms}

Measles is an infectious disease caused by a paramyxovirus, an RNA virus. The clinical manifestation shows many signs of a virus infection. We want to give here an overview about the symptoms but concentrate on mucocutaneous manifestations, as it is mentioned in publications. In the literature two clinical stages are differentiated: the prodromal and the exanthematous ones. Manifestations of the prodromal phase appear after about 11 [4] or 1012 [5] days of incubation. Paediatric dermatology [6] suggests about 14 days until the exanthema appears. Signs and symptoms can include fever of about 39$40^{\circ} \mathrm{C}$, malaise, anorexia, coryza, conjunctivitis, rhinitis, cough, pharyngitis and tracheitis [5-7]. Koplik spots, 'white grey papules on a red background' [6], are also described to appear at the beginning of the disease on the buccal mucosa opposite the lower molars and involving the rest of the mucosa afterwards. Different texts say that Koplik spots are pathognomonic for measles [7-9]. However, they were also ob-

\section{KARGER}

Fax +4161306 1234 E-Mail karger@karger.ch www.karger.com
(C) 2012 S. Karger AG, Basel

$1018-8665 / 12 / 2241-0001 \$ 38.00 / 0$

Accessible online at: www.karger.com/drm
Prof. Peter Itin

Department of Dermatology, University Hospital Basel

Petersgraben 4

$\mathrm{CH}-4031$ Basel (Switzerland)

Tel. +41 61265 4048, E-Mail peter.itin@unibas.ch 

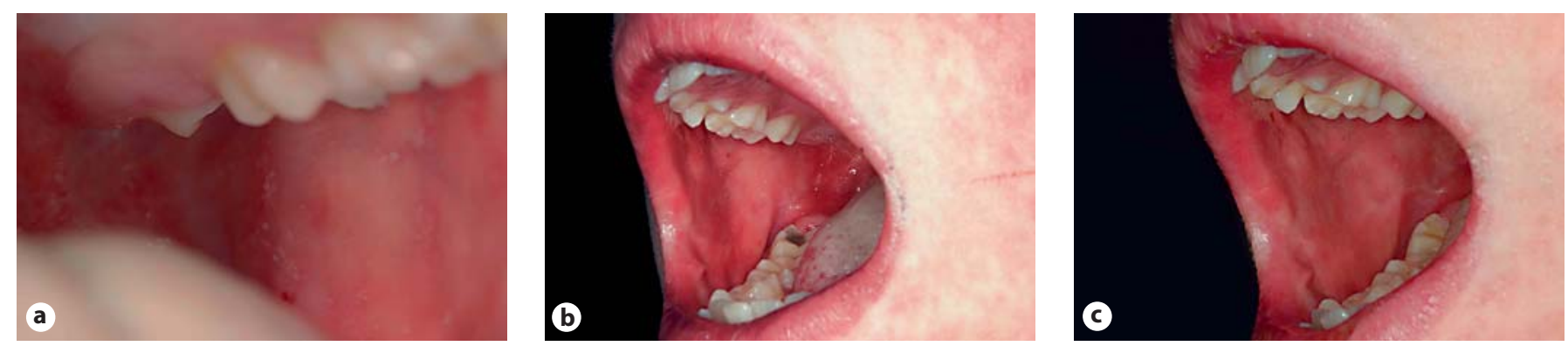

Fig. 1. a-c Koplik spots diffusely spreading on the buccal mucosa from the second to the fourth day.
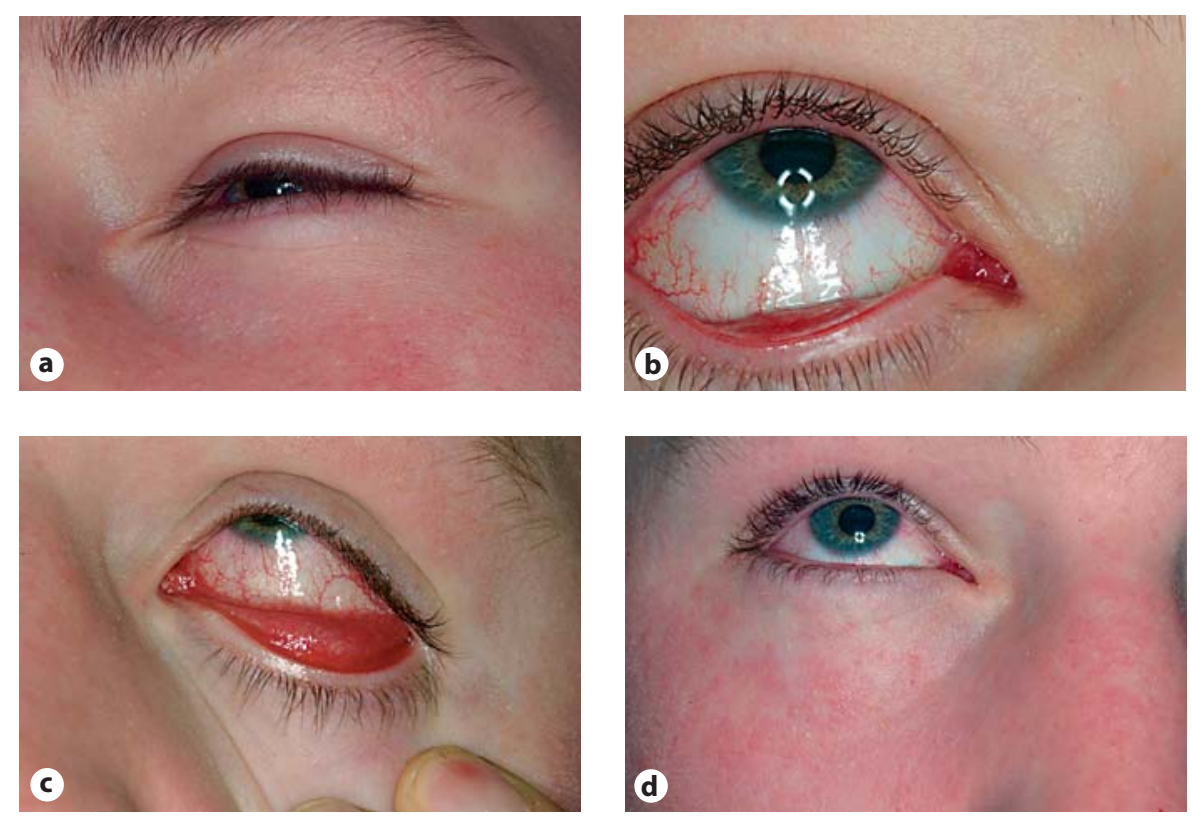

Fig. 2. Conjunctivitis from the eighth (a), ninth (b) and tenth (c, d) day.

served with parvovirus $B_{19}$ infection $[10$, 11]. There are differences concerning the time point, duration and localization of appearance of Koplik spots. The time of appearance is either described as being generally in the prodromal stage $[6,12]$ or just early in the course of infection [13] or 'a couple of days before the rash' [12]. In other sources, they are said to appear on the second or third day of the prodromal stage $[4,7,14]$ or 1 [9] or 2 [15] days before the onset of the skin eruption. Concerning duration, the literature offers two opinions: Koplik spots are either described as persisting until the onset of the exanthema for 2-3 days [7, 9, 15] or just 'for several days' [14]. Most literature locates Koplik spots to the buccal mucosa opposite the upper molars $[6,12,14,15]$ spreading from there to the whole buccal mucosa. The mucous membrane of the inside of the lips [8] as well as occasionally the conjunctiva, the vaginal and gastrointestinal mucosa [12] are also mentioned as localizations of Koplik spots.

Conjunctivitis is either not mentioned at all $[4,14]$ or generally as appearing at the beginning of the prodromal phase [7, 13]. Paediatric dermatology [5] describes conjunctivitis as characterized by 'severe lacrimation and a transverse marginal line of conjunctival injection across the lower lids'.

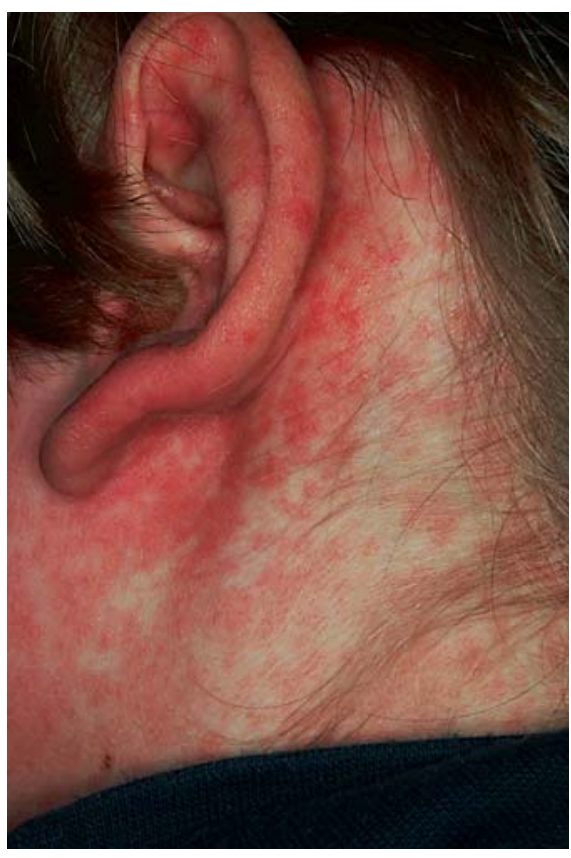

Fig. 3. Exanthema localized behind the ears on the fifth day of the rash.

As mentioned the exanthematous stage appears after the prodromal phase. The rash shows erythematous macules and papules $[5-7,13,15]$ which gradually become confluent. After reaching the climax, the rash turns into a coppery-brown colour and then desquamates $[6,7,14]$.

The onset and the duration of the rash are described differently in the literature. Some textbooks describe the exanthema as appearing 14 days after exposure [6, 15] and lasting for 2-4 days [6] while others indicate about 5 days until the rash begins to fade [15]. An additional variation is the exanthema developing on the third day and desquamating after 4 days. 

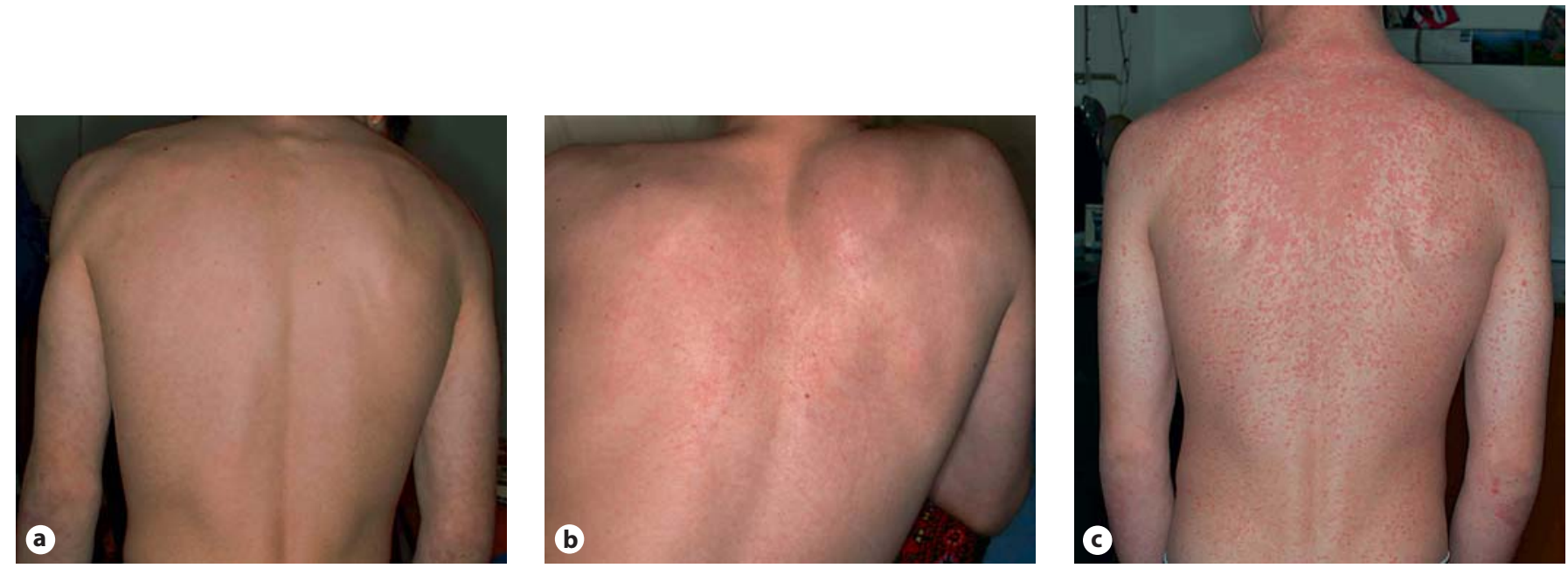

Fig. 4. Exanthema localized to the back on the eighth (a), ninth (b) and tenth (c) day.

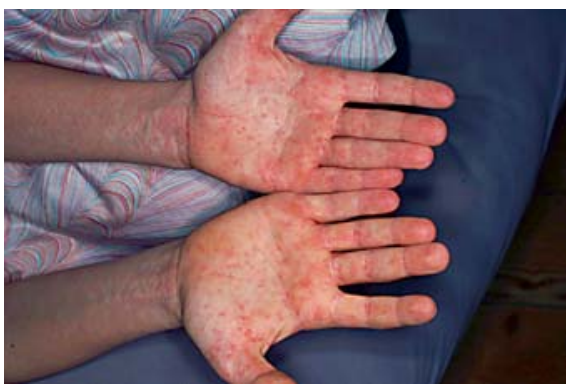

Fig. 5. Involvement of the palms at the peak of the onset of the rash.

The exanthema starts on the face and behind the ears, spreading to the neck and then to the torso and the extremities $[4,14$, $16]$ before disappearing again in the same order $[4,6,7,14,15]$. Other textbooks specifically mention the hairline instead of the face $[6,15]$ or do not indicate the face as starting area [7]. Sparing of the palms and soles is also mentioned [7].

\section{Methods}

After detecting a measles case in the practice of a general practitioner, the siblings of the patient were also monitored. As they had not been vaccinated either, they were also infected with the virus. In the days of the appearance of the clinical signs, especially dermatological signs were
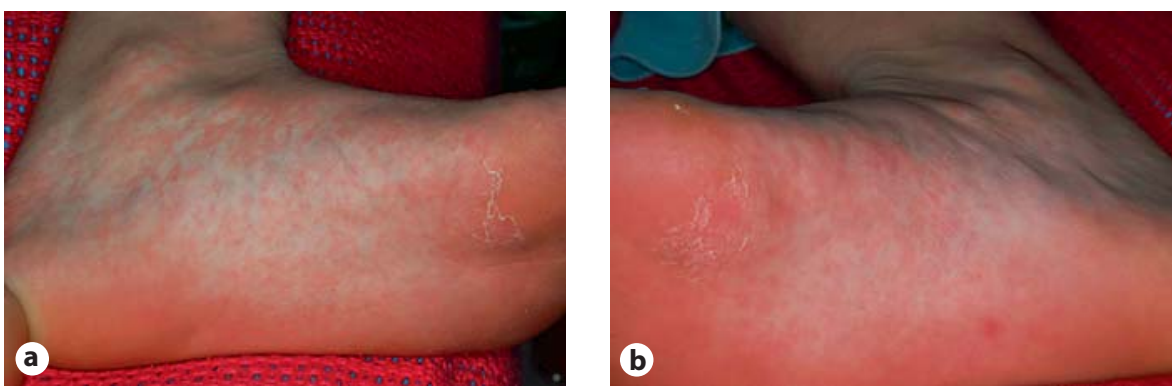

Fig. 6. Exanthema also affecting the sole of the left (a) and right (b) foot on the fourth day.

documented with a digital camera till their disappearance. We set our special focus on Koplik spots, the exanthema and conjunctivitis.

We then described the clinical onset of the symptoms according to morphology, chronological appearance and localization. In a next step we compared the results with the common textbooks on dermatology and articles in Pubmed. We chose 5 books, 3 in English and 2 in German.

\section{Results}

Four patients were monitored during their measles outbreak. The Koplik spots appeared in 1 case on the third day of the prodromal phase, in a second case just after more than a week after start of the monitor- ing. In the second case, the Koplik spots did not precede the rash; they appeared parallel to it. In both cases, Koplik spots were present for about 4 days. In the other cases, the Koplik spots were only recorded on 1 day. They began on the buccal mucosa mostly opposite the upper molars, then spread diffusely. In 1 case, the Koplik spots were already diffusely spread at the beginning, speckling the entire buccal mucosa (fig. 1).

In all cases we observed conjunctivitis. The onset differed from the fourth day of the prodromal phase to the ninth day after monitoring of the disease, which also paralleled the rash. It lasted for about 3 days, in 1 case for 5 days (fig. 2).

Tongue coating was seen almost every time during the investigation. It appeared together with the exanthema and continued for about 4 days. 
The appearance of the rash was variable. It once began on the third day and lasted for about 5 days as in one other patient. In a different case, it appeared on the fifth and started to fade after 7 days.

Regions where the exanthema spread differed as well. In 2 cases, the beginning was on the face and behind the ears (fig. 3) but at the same time discretely on the torso (fig. 4). The rash then spread to the neck and the extremities, and the single lesions became confluent. One of the patients showed involvement of the palms during the climax after the onset on the third day (fig. 5). In a different patient, the soles were affected as well (fig. 6). The rash started to diminish as it appeared after about 4 days. In contrast, the exanthema appeared in 1 case first on the arms and hands (dorsal side). Three days later, the rash spread to the face, behind the ears and to the torso. In addition, a facial oedema was observed on the fifth day of the exanthema in this specific patient. The maximum was reached 1 day later. As in the other cases, the exanthema became confluent before diminishing. The rash consisted of a maculopapular exanthema gradually coalescing before desquamating. One patient showed signs of cutis marmorata at the onset of the exanthema.

\section{Discussion}

When compared to the literature, our results show several differences.

\section{Koplik Spots}

In most descriptions, Koplik spots appear before the exanthematous stage and disappear after the onset of the rash. Our results show that Koplik spots can appear even after the onset of the rash and occur in parallel. Duration is not described in a consistent way in the literature. Some are very precise, others very vague. Here again our observation differs. Koplik spots do not seem to persist for long. Their localization opposite the upper molars is not confirmed in each case.

\section{Conjunctivitis}

Not all textbooks (2 out of 5) mention conjunctivitis although we observed it in each case. And if mentioned, the literature gives 2-4 days in the prodromal phase. However, in our series we have seen that it can also persist into the exanthematous phase.

\section{Exanthema}

Our cases show that the rash can appear earlier than some textbooks suggest. Also, the duration differs in comparison with our cases. Textbooks indicate 5 days or less, while in 1 case exanthema lasted for 7 days.

Regarding the localization where the rash appears first, on the face and behind the ears, the literature matches mostly our observations, but from our findings it seems that the spread occurs earlier. The weak manifestation of the exanthema on the torso and on the arms at the beginning seems to contradict that. It is interesting that one textbook does not mention a starting point at all. The sparing of the palms and soles could be proved wrong.

The morphology of the exanthema was observed as described in the literature. One case though showed signs of cutis marmorata.

In our series we document that the signs and symptoms of measles are not as specific as described in some textbooks. We think that they should be kept more general. A further explanation could be that a shift in clinical manifestation occurred by small modifications of the virus and also the human immune system. To better understand those correlations, a larger number of patients will be needed in a future study.

\section{Disclosure Statement}

All authors have no conflict of interest.

\section{References}

1 Yassunaga H, Shi Y, Takeuchi M, Horiguchi $\mathrm{H}$, Hashimoto H, Matsuda S, Ohe K: Measles-related hospitalizations and complications in Japan. Intern Med 2010;49:19651970.

2 Muscat M, Bang H, Wohlfart J, Glisman S, Molbak K: Measles in Europe: an epidemiological assessment. Lancet 2009;373:383389.

3 Richard J, Massery-Spicher V, Santibanez S, Mankertz A: Measles outbreak in Switzerland - an update relevant for the European football championship. Eur Surveill 2008;13: $1-4$.

4 Grimmel M: Dermatologie, ed 5. Stuttgart, Thieme, 2005.
5 Sabella C: Measles: not just a childhood rash. Cleve Clin J Med 2010;77:207-213.

6 Mancini AJ, Bodemer C: Pediatric Dermatology, ed 3. London, Mosby, 2006.

7 Gröbe H: Pädiatrische Dermatologie, ed 2. Heidelberg, Springer, 2006.

8 Koplik H: The diagnosis of the invasion of measles from a study of the exanthema as it appears on the buccal mucous membrane. Arch Pediatr 1896;13:918-922.

-9 Lefebvre N, Camuset G, Christmann D, Hansemann Y: Koplik spots: a clinical sign with epidemiological implications for measles control. Dermatology 2010;220:280281.

10 Evans LM, Grossman ME, Gregory N: Koplik spots and a purpuric eruption associated with parvovirus $B_{19}$ infection. J Am Acad Dermatol 1992;27:466-467.
Boralevi F: Measles: an ongoing story. Dermatology 2010;220:193.

12 Steichen O, Dautheville S: Koplik spots in early measles. Can Med Assoc J 2009;180: 583.

13 Katz J, Guelmann M, Stavropoulus F, Heft M: Gingival and other oral manifestations in measles virus infection. J Clin Periodontol 2003;30:665-668.

14 Fölster-Holst R: Dermatology, ed 3. Heidelberg, Springer, 2009.

15 Krafchik BR: Textbook of Pediatric Dermatology. Oxford, Blackwell Science, 2000.

16 Yoshida M, Yamada Y, Kawahara K, Itoh M: Development of follicular rash in measles. $\mathrm{Br}$ J Dermatol 2005;153:1226-1228. 